\title{
HIDING IN PLAIN SIGHT OR GOING BEYOND THE DUODENAL PAPILLA: A CASE SERIES
}

\author{
Ruxandra OPRITA ${ }^{1,2} \bowtie$, Gabriel CONSTANTINESCU ${ }^{1,2}$, Teodor BEREA ${ }^{2}$, Diana DIACONESCU², \\ Lidia STEFAN ${ }^{2}$ \\ ${ }^{1}$ University of Medicine and Pharmacy "Carol Davila”, Bucharest, Romania \\ ${ }^{2}$ Gastroenterology Clinic, Clinical Emergency Hospital of Bucharest, Bucharest, Romania
}

Received 02 Febr 2021, Accepted 01 March 2021

https://doi.org/10.31688/ABMU.2021.56.1.13

\begin{abstract}
Introduction. The tumours of the small intestine are rare findings. These tumours are more common in the duodenum than in the jejunum and ileum. The symptoms are vague and non-specific. A complete and thorough esophagogastroduodenoscopy plays a crucial role in the early diagnosis of small bowel tumours, especially those localized after the second part of the duodenum.

Case presentations. The first case is of a 43-year-old man, who presented for important weight loss (19 kilograms in one year). The upper digestive endoscopy revealed a tumour in the third part of the duodenum, with a positive biopsy for non-Hodgkin's lymphoma. The second case is of a 63-year-old male smoker patient, who presented to the emergency department for melena. While the emergency upper digestive endoscopy was non-diagnostic, a second evaluation highlighted a mass in the third part of the duodenum, that macroscopically and subsequently microscopically was confirmed to be a gastrointestinal stromal tumour. The third case is of a 59-year-old woman who presented for abdominal pain and in whom echo-endoscopy diagnosed a duodenal tumour.
\end{abstract}

\section{Résumé}

Cacher à la vue ou aller au-delà de la papille duodénale? Une série de cas

Introduction. Les tumeurs de l'intestin grêle sont une découverte très rare, tandis que le duodénum en est la partie la plus touchée, avec une proportion de tumeurs plus élevée que le jéjunum et l'iléon. Les symptômes sont vagues et non spécifiques. Une œsophagogastroduodénoscopie complète et approfondie joue un rôle crucial dans le diagnostic précoce des tumeurs de l'intestin grêle, en particulier celles situées au-delà de la deuxième partie du duodénum.

Présentations de cas. Le premier cas est celui d'un homme de 43 ans avec une perte de poids importante (19 kilogrammes en un an). L'endoscopie supérieure a diagnostiqué une tumeur dans la troisième partie du duodénum avec une biopsie positive pour un lymphome non-Hodgkinien. Le deuxième cas est celui d'un patient fumeur de sexe masculin âgé de 63 ans qui s'est présenté au service des urgences pour méléna. Alors que l'endoscopie gastro-intestinale supérieure d'urgence n'était pas diagnostique, une deuxième évaluation a mis en évidence une masse dans la troisième partie du duodénum qui, macroscopiquement, puis 
Conclusions. While many duodenal tumours become symptomatic when they are locally advanced, an incomplete upper digestive endoscopy may further delay the diagnosis and worsen the outcome. This highlights the importance of performing a complete esophagogastroduodenoscopy with the visualisation of the entire duodenum.

Keywords: duodenum, tumours, esophagogastroduodenoscopy, weight loss.

\section{INTRODUCTION}

Primary neoplasms of the small intestine are a very rare finding, accounting for about $0.3 \%$ of all gastrointestinal tumours ${ }^{1}$. When comparing the most often sites of neoplasms inside the small intestine, the duodenum has a higher proportion of tumours when compared to the jejunum and ileum. Duodenal carcinomas account for $20-25 \%$ of all small bowel malignancies, whereas sarcomas, carcinoid and lymphomas are less common ${ }^{2}$. One large population study has found that duodenum represents the site of adenocarcinoma of the small intestine in $55.7 \%$ of cases, most cases being reported in the second part of the duodenum (D2), followed by the third/fourth parts (D3/D4), cancers of the first part (D1), especially the duodenal bulb, being extremely rare ${ }^{3}$. This low incidence has three possible explanations: (a) because of the more fluid content passing through, there is less mechanical damage of the mucosa; (b) the transit time inside the duodenum is faster, so the contact per unit of length is reduced and (c) the mucosal cells have a much higher turn-over rate than those of the colon ${ }^{4}$.

Duodenal tumours pose diagnostic difficulties because of their non-specific symptoms and their rarity and because during esophagogastroduodenoscopy (EGD) the duodenum is mostly overlooked. We report the cases of two male and one female patients in whom EGD and endoscopic sonography (EUS) have been carried out further than usual, because of high suspicion.

\section{Cases presentation}

The first case is of a 43-year-old male with no significant medical history, who presented to the microscopiquement, s'est avérée être une tumeur stromale gastro-intestinale. Le troisième cas est celui d'une femme de 59 ans qui s'est présentée à l'hôpital pour des douleurs abdominales et qui a subi une écho-endoscopie pour une masse duodénale.

Conclusions. Alors que de nombreuses tumeurs duodénales deviennent symptomatiques lorsqu'elles sont localement avancées, une endoscopie gastro-intestinale supérieure incomplète peut retarder davantage le diagnostic et aggraver le résultat. Cela met en évidence l'importance d'effectuer une œsophagogastroduodénoscopie complète avec la visualisation de l'ensemble du duodénum.

Mots-clés: duodénum, tumeur, œesophagogastroduodénoscopie, perte de poids.

emergency department for fatigue, malaise and important involuntary weight loss (approximately 19 kilograms in 12 months), night sweats and fever. Although non-specific, these symptoms were the reason to investigate the patient further, by performing EGD and colonoscopy. The patient underwent EGD and the initial findings along the oesophagus, stomach, duodenal bulb and second duodenum were non-diagnostic. The decision was made to advance the endoscope further down, and when entering the D3 we encountered a large mass that occupied approx. $50 \%$ of the circumference of the intestinal lumen (Fig. 1, 2). Biopsies were taken.

While waiting the results of the biopsies, the patient was investigated further and the blood tests revealed severe anaemia, with a haemoglobin of 7.1 $\mathrm{g} / \mathrm{dL}$, and a mild thrombocytosis of $376.9 \times 10^{3} /$ $\mu 1$. Thorax and abdominal computed tomography revealed a lympho-proliferative process with hepato-splenomegaly, supra and subdiaphragmatic lymph nodes organized in a large retroperitoneal mass that infiltrates the D3, with hepatic, splenic and renal metastases. Further biopsies were taken from a cervical lymph node for immunohistochemistry, under local anaesthesia. The biopsies taken from the duodenal tumour yield the following result: low-grade small cell non-Hodgkin's lymphoma. The patient was referred to the surgical department.

The second case is of a 63-year-old male smoker patient, with history of stage 2 arterial hypertension and chronic obstructive pulmonary disease, who presented to the emergency department for melena and fatigue. The blood tests detected severe anaemia, with a haemoglobin of $6 \mathrm{~g} / \mathrm{dL}$. Emergency EGD was performed and no active signs of bleeding were found. The patient was admitted in the gastroenterology ward and a second EGD was performed a few 


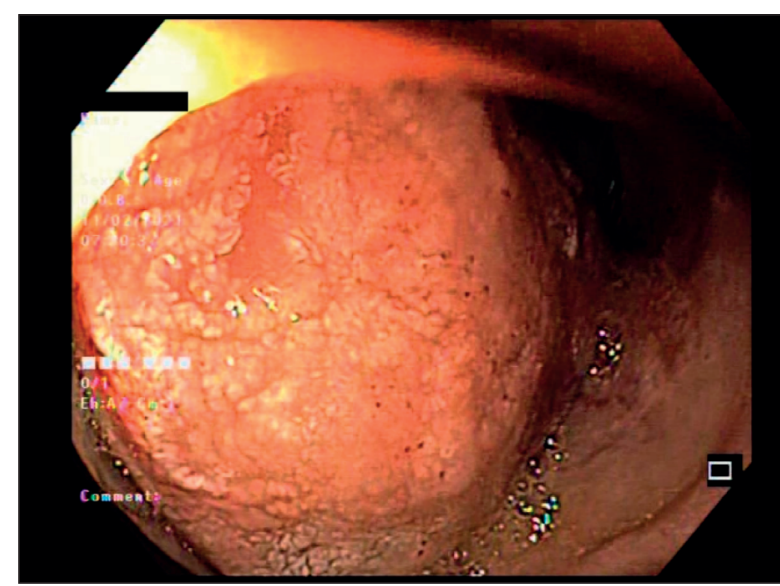

Fig. 1. Esophagogastroduodenoscopy (EGD) -

a D3 mass that raised the suspicion of duodenal invasion.

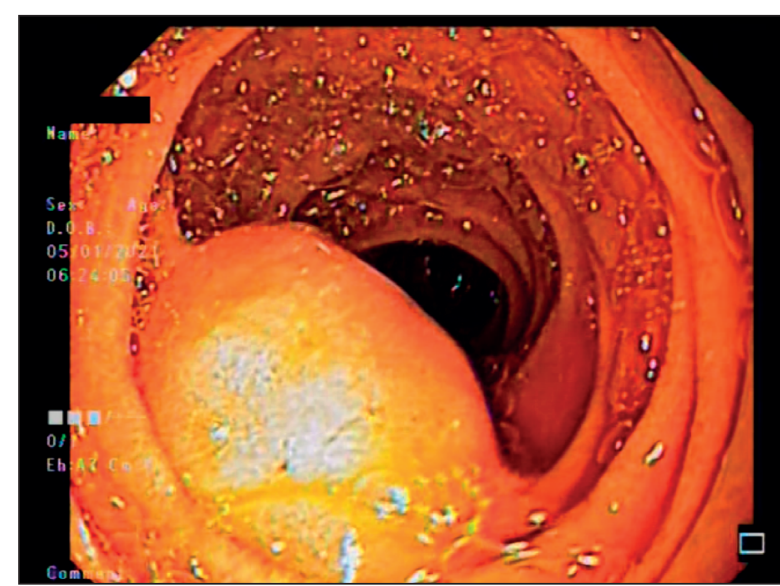

Fig. 3. Esophagogastroduodenoscopy (EGD) -

a D3 mass that occupies $>50 \%$ of the intestinal lumen; macroscopic aspect of a GIST.

days after the patient was stabilized. During the second EGD, a submucosal mass was detected, of approximately $2 \mathrm{~cm}$, occupying $>50 \%$ of the intestinal lumen, that has normal mucosal lining, with a central ulcerated depression, tender to the touch (Fig. 3). Biopsies were taken. The macroscopic aspect was of a gastrointestinal stromal tumour (GIST). The histopathological microscopic results confirmed a GIST, that is DOG1, CD117 and CD34 positive on immunohistochemistry, without microscopic malignancy criteria.

The third case is of a 59-year-old woman who presented for abdominal pain, fatigue and dizziness. Prior to the current presentation she underwent an EGD, that was non-diagnostic, and because of the persistence of symptoms she decided to ask for a second opinion. Blood tests showed a moderate anaemia (haemoglobin $8.7 \mathrm{~g} / \mathrm{dL}$ ) and thrombocytosis of $429 \times 10^{3} /$ $\mu \mathrm{l}$. EGD was performed and a D2 mass was found, with a macroscopic aspect of a GIST. The biopsies

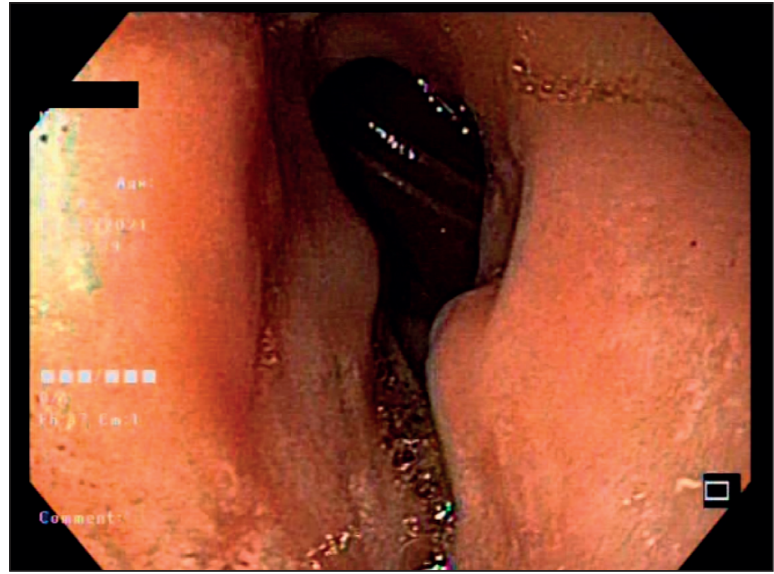

Fig. 2. Esophagogastroduodenoscopy (EGD) important doudenal stenosis.

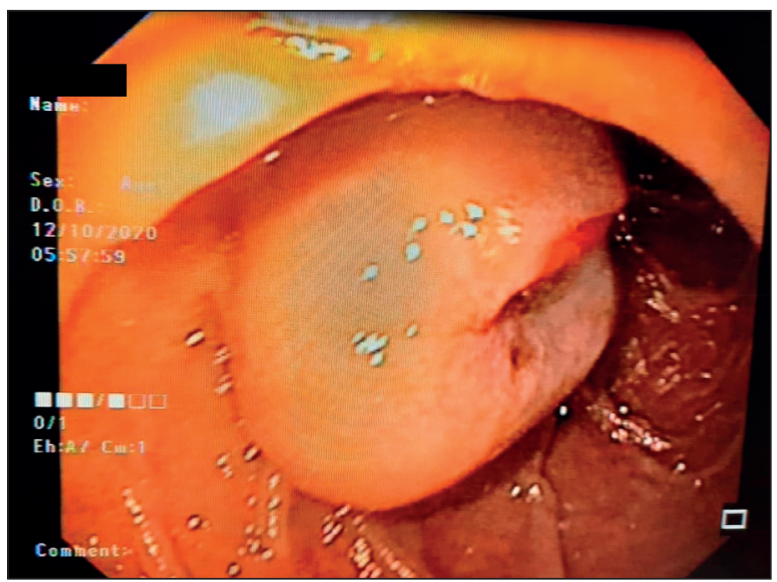

Fig. 4. Esophagogastroduodenoscopy (EGD - a D2 tumour with a central ulceration.

were negative for a malignant transformation, prompting the necessity of EUS, that visualized a $2.5 / 2 \mathrm{~cm}$ submucosal tumour, near the ampulla, with a central ulceration, and high vascularity on Doppler examination (Fig 4). The tumour was biopsied using fine needle biopsy (FNB), that was positive for a GIST, with immunohistochemistry positive for CD117.

\section{Discussion}

The third and fourth parts of the duodenum are often overlooked on upper digestive endoscopy. Its location, with both intraperitoneal and retroperitoneal segments and proximity to the gallbladder, pancreas, stomach, spine, aorta, liver, and other segments of the gastrointestinal tract, results in duodenal involvement by a multitude of primary and secondary tumours $^{57}$.

The evaluation by upper digestive endoscopy plays a crucial role in the diagnosis of gastrointestinal 
tract tumours. Duodenal tumours may pose diagnostic challenges, because most often the symptoms are vague and appear late, when the local extension is important $t^{8-10}$. The most frequent symptom is abdominal pain $\left(56 \%\right.$ of cases) ${ }^{11}$, followed by malaise, nausea, weight loss, fatigue, weakness, anaemia and gastrointestinal bleeding or obstruction. EGD is the preferred diagnostic method and it is crucial to be performed by an experienced endoscopist, because of the necessity to evaluate the entire duodenum ${ }^{3}$.

In a study by Zhang et al, EGD was the main diagnostic investigation for primary duodenal cancer, detecting $88.6 \%$ of the tumours ${ }^{11}$. Sometimes, the localization of duodenal tumours is inaccessible to endoscopic viewing, which may result in a failure to detect them during the examination ${ }^{12}$.

GISTs are a type of non-directional differentiation tumours that independently originate from the primitive mesenchymal tissues of the gastrointestinal tract ${ }^{13}$. The incidence of GISTs is approximately 1-2 $/ 200,000$, and they may occur across the length of the entire digestive tract, the most affected sites being the stomach and the small bowel, while tumours of the duodenal stroma are less frequent, representing only $10 \%$ of the small intestine tumours ${ }^{14}$. Duodenal stromal tumours are mostly localized in the descending and horizontal portion of the duodenum, and less often in the bulb and ascending portion. Some authors have reported that recurrent black stool is the most common clinical symptom of a duodenal stromal tumour ${ }^{13}$.

The gastrointestinal tract is the most common extranodal site of involvement by non-Hodgkin's lymphoma. Primary lymphomas of the small intestine are relatively rare and account for $4-12 \%$ of all non-Hodgkin's lymphomas and $19-38 \%$ of small bowel malignancies. Intestinal lymphomas usually manifest with symptoms like dyspepsia, abdominal pain, diarrhoea, loss of weight, nausea and vomiting, night sweats and fever. Jaundice is a very rare initial presenting sign of intestinal lymphomas and is seen only in $0.2-0.5 \%$ of all cases ${ }^{15}$. Hystologically, $80-90 \%$ of primary gastrointestinal lymphomas are of B-cell origin. Mucosa-associated lymphoid tissue is the most common subtype of duodenal lymphomas, followed by diffuse large cell. The survival is largely dependant on the histological grade and disease stage, with a higher survival rate for B-cell lymphoma than for T-cell lymphoma ${ }^{1,16}$.

The optimal treatment strategy for primary intestinal lymphoma is still a matter of debate, with surgical resection and chemotherapy being the most preffered methods of treatment, the their combination proving superior to any other treatment, leading to better survival rates. In a study by Kim et al., surgical resection was associated with survival benefits in patients with B-cell lymphoma $(\mathrm{p}<0.001)^{17}$.

\section{Conclusions}

EGD with visualisation of the third part of the duodenum is an essential investigation for the diagnosis of certain small bowel tumours. While many tumours become symptomatic after the disease is already advanced, it is crucial to pay increased attention when performing a diagnostic EGD. Not performing a full examination of the duodenum might result in a further delay in the diagnosis and treatment of the patient, with negative impact on the outcome of the disease. Repeated endoscopy may be effective, even if is costly, in selected patients.

\section{Author Contributions:}

R.O., G.C., D.D., T.B. and L.S. were responsible for the diagnostic procedures, clinical diagnosis, and treatment decisions. R.O., T.B. and D.D. wrote the manuscript. All authors have read and agreed to the published version of the manuscript.

\section{Compliance with Ethics Requirements:}

"The authors declare no conflict of interest regarding this article"

"The authors declare that all the procedures and experiments of this study respect the ethical standards in the Helsinki Declaration of 1975, as revised in 2008(5), as well as the national law. Informed consent was obtained from all the patients included in the study"

"No funding for this study"

\section{Acknowledgements:}

None

\section{References}

1. Bal A, Joshi K, Vaiphel K, Wig JD. Primary duodenal neoplasms: A restrospective clinico-pathological analysis. World J Gastroenterol. 2007;13(7):1108-1111.

2. Kaminski N, Shaham D, Eliakim R. Primary tumours of the duodenum. Postgrad Med J. 1993;69(808):136-138.

3. Cloyd JM, George E, Visser BC. Duodenal adenocarcinoma: Advances in diagnosis and surgical management. World $J$ Gastrointest Surg. 2016;8(3):212.

4. Negri E, Bosetti C, La Vecchia C, Fioretti F, Conti E, Franceschi S. Risk factors for adenocarcinoma of the small intestine. Int J Cancer. 1999;82(2):171-174.

5. Jayaraman M V, Mayo-Smith WW, Movson JS, Dupuy DE, Wallach MT. CT of the duodenum: an overlooked segment gets its due. Radiographics. 2001;21:S147-60. 
6. Socea B, Nica AA, Bratu O, et al. Incidental finding of a sigmoid intussusception associated with rectal prolapse - a case report. Arch Balk Med Union. 2018;53(1):143-146.

7. Diaconu CC, Arsene D, Balaceanu A, Bartos D. A rare tumor revealed by abdominal trauma: case presentation. Romanian Journal of Morphology and Embryology. 2014;55(3): 973-976.

8. Markogiannakis $\mathrm{H}$, Theodorou $\mathrm{D}$, Toutouzas $\mathrm{KG}$, Gloustianou G, Katsaragakis S, Bramis I. Adenocarcinoma of the third and fourth portion of the duodenum: a case report and review of the literature. Cases J. 2008;1(1):98.

9. Cunningham JD, Aleali R, Aleali M, Brower ST, Aufses AH Malignant small bowel neoplasms: Histopathologic determinants of recurrence and survival. Ann Surg. 1997;225(3): 300-306.

10. Draghici T, Negreanu L, Bratu OG, et al. Paraneoplastic syndromes in digestive tumors: a review. Romanian Biotechnological Letters. 2019;24(5):813-819.

11. Zhang S, Cui Y, Zhong B, et al. Clinicopathological characteristics and survival analysis of primary duodenal cancers:
A 14-year experience in a tertiary centre in South China. Int J Colorectal Dis. 2011;26(2):219-226.

12. Barnes G, Romero L, Hess KR, Curley SA. Primary adenocarcinoma of the duodenum: Management and survival in 67 patients. Ann Surg Oncol. 1994;1(1):73-78.

13. Wang Z, Ding Z, Huang S, Zhong S. Experience in clinical diagnosis and treatment of duodenal tumors. Mol Clin Oncol. 2016;5(6):731-739.

14. Yildirgan MI, Bașoğlu M, Atamanalp SS, Albayrak Y, Gürsan N, Önbaș Ö. Duodenal stromal tumor: report of a case. Surg Today. 2007;37(5):426-429.

15. Yildirim N, Öksüzoğlu B, Budakoğlu B, et al. Primary duodenal diffuse large cell non-hodgkin lymphoma with involvement of ampulla of Vater: report of 3 cases. Hematology. 2005;10(5):371-374.

16. Pan SY. Epidemiology of cancer of the small intestine. World J Gastrointest Oncol. 2011;3(3):1.

17. Kim SJ, Choi CW, Mun YC, et al. Multicenter retrospective analysis of 581 patients with primary intestinal non-Hodgkin lymphoma from the Consortium for Improving Survival of Lymphoma (CISL). BMC Cancer. 2011;11(1):321. 